\title{
GP commissioning consortia: is there a role for physician assistants in routine care?
}

With the publication of the government's health White Paper, ${ }^{1}$ and the impending handover of commissioning to GPs, the future of family medicine, and indeed the $\mathrm{NHS}$, is at a crossroads.

According to the White Paper, every GP will have to join a commissioning consortium by 2011/12; and primary care trusts (PCTs) will be abolished in $2013 .{ }^{1}$

Commissioning will take up a lot of GP time and doctors, who are already involved in patient care and management of their organisations and business, will have even less time to devote to patient care.

The leader of the British Medical Association and the General Practitioners Committee warned GPs earlier in the week of the extent of the task ahead; as the time required for commissioning will be substantial. The warning was accompanied by a gentle nudge towards hiring NHS managers instead of private sector consultants. $^{2}$

Considering the diverse nature of the work currently undertaken by PCTs - all 152 of them - radical change to the way GPs currently work is essential for the new model to be successful.

Paul Charlson, a member of the Doctors for Reform steering committee and himself a GP, has warned of the need for a culture change in general practice in preparation of GP consortia. ${ }^{3}$

Dr Charlson warned that the burden will fall to a few GPs who are interested in commissioning, while other GPs will have to focus on more complex tasks.

This leaves a gap for the management of repetitive and so-called 'low challenge' tasks which GPs have to deal with.

Although repetitive and seemingly unchallenging, these cases still need to be dealt with for the improvement of the health of the general population. Also, this could potentially widen health inequality gaps with doctors working in areas of relatively higher deprivation whose practices are currently understaffed and could increase concerns about impending retirement of GPs from South Asia who are the 'backbone of the medical labour force' in inner city neighbourhoods. ${ }^{4}$

While it is still unclear what the final picture will be, it is worth considering ways to handle the gap in patient care which these proposed arrangements will almost certainly create. Physician assistants in primary care could offer a realistic solution to fill the gaps in care which will be created by the reorganisation of GP tasks.

In view of the responsibility that GPs will be taking for commissioning, the introduction of physician assistants into primary care would free up GP time to manage more complex cases, to mentor, supervise, to provide primary care leadership, to improve quality of care, and to focus on commissioning. An estimated $70-80 \%$ of tasks previously carried out only by physicians can be done by physician assistants at the same level of quality. ${ }^{5}$ Much of the burden of paperwork imposed on doctors may also be handed over to physician assistants. This fits the ethos of introducing physician assistant practice in the UK: the National Practitioner Programme, while active stated that the role was intended 'to take over all the repetitive and protocol based work which doctors do'. ${ }^{6}$

\section{The Physician Assistant}

The shortage of doctors and expense of their training led to development of alternative health professionals to carry out routine and repetitive tasks under supervision of doctors. Physician assistants were licensed in the 1960s in the US mainly to expand capacity in primary care where doctors were often over-worked in rural and medically under-served areas. ${ }^{5,7,8}$

Graduates with a good science degree are offered training which comprises an intensive 2 year curriculum similar to a condensed traditional medical course. ${ }^{9}$

Conceptually within a 'medical model', the training for physician assistants aims for competency in history taking, examination, diagnosis, management, and referral. In the US physician assistants take a national certification exam to qualify, and have to be recertified by examinations every 6 years. ${ }^{5}$ Similarly, surgical care practitioners, who work as permanent members of the surgical team carrying out minor procedures and as surgeons' assistants, were introduced in the UK in 1989. ${ }^{10}$ Physician assistants have been shown to provide patient care that is indistinguishable from the quality of care provided by physicians. ${ }^{8,11}$ As they have a smaller caseload, physician assistants are able to give more time to each individual, ${ }^{12,13}$ similar to the nurse practitioner, and high levels of patient satisfaction with physician assistants have been recorded in several studies. ${ }^{7,14}$

Physician assistants are regarded to be cost-effective as they reduce the workload of doctors at a lower cost. ${ }^{15}$ In one study in the US using physician assistants for regular visits (3-4 per week) to a nursing home (with supervision from physicians), the authors found reduced hospitalisation and medical costs compared with the routine policy of monthly physician visits. ${ }^{16}$ The physician assistant training programme attracts graduates previously under-utilised by the $\mathrm{NHS}$, such as science graduates, those interested in working in health but not attracted to nurse training, and those who desire flexible working conditions.

In the US, applicants were initially predominantly men but women now comprise over $60 \%$ of working physician assistants. Physician assistants have been prepared to work in areas where GPs are difficult to recruit, and so could be directed to work in areas of deprivation as another step towards tackling health inequalities. Physician assistants could be commissioned by GPs to address inequalities in access to health care and 'hard to reach' groups that do not attend for chronic disease annual reviews and are not captured by the Quality and Outcomes Framework as they are reported as exceptions. The recruitment of physician assistants to more deprived areas, may inadvertently attract GPs to work there 
because of the reduced workload and better staff ratios, as they are able to devote more time to commissioning.

With radical reforms of the NHS, the introduction of these healthcare professionals has the potential to improve health outcomes and free up GP time to focus on commissioning.

\section{Olumide Elegbe}

\section{REFERENCES}

1. Department of Health. Equity and excellence: liberating the NHS. London: Department of Health, 2010. http://www.dh.gov.uk/prod_consum_dh/groups/dh_di gitalassets/@dh/@en/@ps/documents/digitalasset/dh_1 17794.pdf (accessed 9 Aug 2010).

2. Gainsbury S. BMA leader urges GPs to hire NHS managers rather than private companies. Health Serv J 2010, 19 July: http://www.hsj.co.uk/news/primarycare/bma-leader-urges-gps-to-hire-nhs-managersrather-than-private-companies/5017376.article (accessed 9 Aug 2010).

3. Ford S. GP consortia will be a 'minority' interest. Health Serv J 2010, 21 July: http://www.hsi.co.uk/5017350.article?referrer=e2 (accessed 9 Aug 2010).

4. Gavin M. Physician assistants. Many general practitioners would welcome having physician assistants. BMJ 2002; 324(7339): 735. [Letter] http://www.bmj.com/cgi/content/extract/324/7339/735 (accessed 9 Aug 2010).

5. National Practitioner Programme 2006 - Recorded interview.

6. Buchan J, O'May F, Ball J. New role, new country: introducing US physician assistants to Scotland. Hum Resour Health 2007, 5: 13.

7. Frary T. A New Definition of 'Physician Assistant'. J Am Acad Physician Assist 1996; 9: 22-27.

8. Mittman DE, Cawley JF, Fenn WH. Physician Assistants in the United States. BMJ 2002; 325: 485-487.

9. Hutchinson L, Marks T, Pittilo M.The physician assistant: would the US model meet the needs of the NHS? BMJ 2001; 323: 1244-1247.

10. Abood A. Surgical Care Practitioners. BMJ Careers 2005; 26 Nov: 227.

11. White GL Jr, Davis AM. Physician Assistants as partners in physician directed care. Southern Med J 1999; 92: 956-960.

12. Wilson IB Landon BE, Hirschhom LR, et al. Quality of HIV Care provided by nurse practitioners, physician assistants and physicians. Ann Int Med 2005; 143(10): 729-737

13. Horrocks S, Anderson E, Salisbury C. Systematic review of whether nurse practitioners working in primary care can provide equivalent care to doctors. BMJ 2002; 324: can provide 823 .

14. Stewart A, Catanzaro. Can Physician Assistants be Effective in the UK? Clin Med 2005; 5: 344-348.

15. Chopra M, Munro S, Lavis JN, et al. Effects of policy options for human resources for health: an analysis of systematic reviews. Lancet 2008; 371: 668-674.

16. Ackermann RJ, Kemle KA.The effect of a physician assistant on the hospitalisation of nursing home residents. J Am Geriatr Soc 1998: 46; 610-614.

\section{EDO - called to the dance!}

The European Doctors Orchestra (EDO) came away from the vertiginous heights of last summer's achievement in Poznan where, with sublime impudence, the orchestra performed Beethoven's Ninth on 3 days' rehearsal, returning to London for its November concert in the Duke's Hall of the Royal Academy. The programme there also stretched it, but without that acute sense of striving for the greatest of all musical summits; in comparison, it was almost a 'pop' programme but one which showed off its strengths. The William Tell Overture was played with a lovely opening cello choir, an almost filigree delicacy of string playing in the overture's midsection, and a huge hurtling excitement in the coda. The orchestra moved next into Mahler's world of anguish and lost love, Lieder eines fahrenden Gesellen - by far the most difficult piece in the programme - and managed beautifully this sudden emotional switch, as evidenced by the tactful and sympathetic accompaniment of the baritone soloist John Ward. After that, it was glorious extroversion all the way, with EDO revelling in the technicolour travelogues of Scheherezade.

This summer, EDO went north to Edinburgh; we played to a packed house, in Greyfriars Kirk and between times were able to soak up the atmosphere of tourist tat and broad avenues and that wonderful weathered yellow sandstone. Some of us touched the hem of history by eating in the very restaurant where JK Rowling, then a single parent with a very young baby, would sit for hours over one cup of coffee as she worked on the first of the Harry Potter books.

As we played Hamish MacCunn's overture 'Land of Mountain and the Flood'; we were joined by the brilliant Josephine Robertson, a natural sciences student at Cambridge, as our soloist in Bruch's G Minor Violin Concerto, and our symphony was Dvorak's Eighth - on which we fell delightedly as one would an old friend. The work is a total joy, in contrast to the tragedy-inspired music produced by so many of Dvorak's contemporaries. The great trumpet calls at the start of the last movement recall Raphael Kubelik's comment at a rehearsal: 'Gentlemen, in Bohemia the trumpets call not to battle but to the dance!'. And that, indeed, was where we were called - to a céilidh, in the hallowed halls of the Royal College of Physicians. For some it was the first taste of Haggis and for many more it was the first time on a Scottish country dance floor, persuaded by the driving rhythms of an excellent band. We scrambled round the floor in the Gay Gordons, the Eightsome Reel, the Dashing White Sergeant, and many others, with hosts of willing hands pushing and pulling us through their snaking intricacies - after which any residual social ice was well and truly cracked!

And next? We play, again in the Duke's Hall in November. Our programme is something of a departure in that it is entirely English ... Elgar Cockaigne, Walton Viola Concerto, and Vaughan Williams 'London Symphony': 21st November, at $3.00 \mathrm{pm}$. We will be supporting Save the Children, and hope to see you there.

\section{Michael Lasserson}

DOI: 10.3399/bjgp10X515610 